\title{
95 Jahre Kompetenz in Befestigungsmaterialien
}

Das japanische Unternehmen GC feiert 2016 fast ein Jahrhundert Lösungskompetenz im Bereich Zementierung: Vor 95 Jahren gründeten 3 junge Chemiker das GC Chemicals Research Laboratory nahe Tokio. Zwar konnte sich ihre 1. Materialentwicklung, ein Standardzement, noch

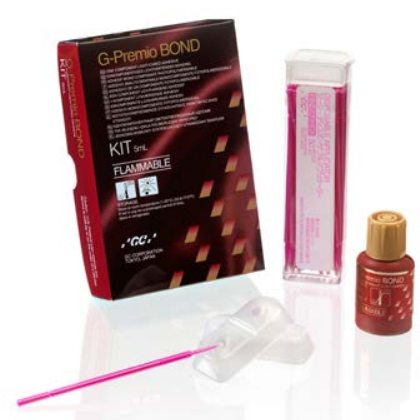

nicht am Markt etablieren - doch dies befeuerte den Innovationstrieb umso mehr und sie legten mit der Spezialisierung auf Befestigungsmaterialien das Fundament für den bis heute währenden Erfolg.

Schon 1925 präsentierten die Forscher einen Kristallin-Zement, der auf der Hauptversammlung der japanischen Zahnärztevereinigung begeistert aufgenommen wurde. Damit war der Grundstein im Bereich Zementierung gelegt - der von Klassikern wie der Fuji-Reihe hin zu aktuellen Produktentwicklungen wie G-CEM LinkForce reicht. Der konventionelle Glasionomerzement (GIZ) Fuji I kann über 25 Jahre dokumentierte Anwendung vorweisen, ist als Pulver und in Kapselform erhältlich und stellt ohne Haftvermittler ein praktisches Material für Befestigungen von metallbasierten Restaurationen und (zirkonbasierten) Vollkeramikkronen und Brücken dar. Mit seiner guten Randab- dichtung und der hohen Biokompatibilität ist dieser Glasionomerzement von GC immer noch ein wahrer Dauerbrenner.

Detaillierte Informationen zu den Befestigungsmaterialien sowie zum kompletten GC-Produktportfolio sind abrufbar unter: www.gceurope.com/local/germany

Nach einer Pressemitteilung der GC Germany GmbH, Bad Homburg www.germany.gceurope.com

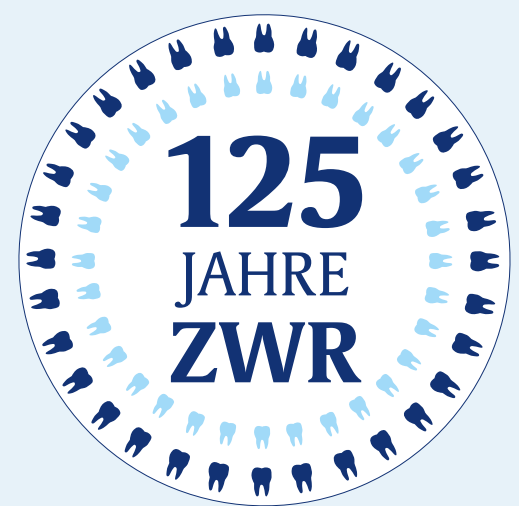

